\title{
LONG TERM DEFORMATION OF BEAMS AND COLUMNS OF HIGH PERFORMANCE CONCRETE
}

\author{
Chatarina Niken $^{1 *}$, Elly Tjahjono ${ }^{2}$, Franciscus Supartono $^{3}$ \\ ${ }^{1}$ Department of Civil Engineering, Faculty of Engineering, University of Lampung, 35145, Indonesia \\ ${ }^{2}$ Department of Civil Engineering, Faculty of Engineering, Universitas Indonesia, Kampus UI \\ Depok, Depok 16424, Indonesia \\ ${ }^{3}$ PT. Partono Fondas Engineering Consultant, JL. KH. Hasyim Ashari, No. 125, Central Jakarta \\ City 10150, Indonesia
}

(Received: August 2017 / Revised: July 2017 / Accepted: October 2017)

\begin{abstract}
The columns of a building must be stronger than the beams. The aim of this study is to obtain the cause of the long-term deformation difference by shrinkage between the beams and columns of high performance concrete with compressive strength of $60 \mathrm{MPa}$. This research was done experimentally in Indonesia during 410 days. Specimens measuring $150 \mathrm{~mm} \times 150 \mathrm{~mm} \times 600$ $\mathrm{mm}$ were used, 3 pieces for the beams and 2 pieces for the columns. Deformation was obtained by using an embedded vibrating wire strain gauge for each specimen. The difference of long-term deformation in columns and beams is in their autogenous deformation behavior. This is because during the autogenous phase, swelling abnormally occurs in the column before shrinkage occurs. The abnormal swelling is caused by the press of its own weight. This phenomenon does not occur in beams. In the age range of 1 to 200 days, the behavior of the beam deformation has a similar pattern to the deformation behavior of the column with a high deformation rate. After that, at 200-410 days, column deformation changes to a very slow deformation rate. Long-term deformation in columns is lower $(64 \%)$ than in the beams at 410 days age.
\end{abstract}

Keywords: Beam; Column; Concrete; Deformation; Shrinkage

\section{INTRODUCTION}

Deformation is the most important mechanism in structure. The understanding of deformation makes structure designers have certain descriptions that are needed in designing. Long-term deformation prediction is important to make the design effective and efficient. Deformations in concrete occur naturally right after casting. It is caused by the hydration process. Long-term deformation is a deformation in the time span of 170-1,000 days (Pons et al., 2003), while the hydration time period is estimated to be 416 days (Morin et al., 2002). Deformation is also affected by pozzolanic admixture (micro silica, silica fume and high reactive metakaolin). Pozzolanic admixture and fiber have been proven and shown to affect compressive strength (Adel $\&$ Ahmed, 2015; Adel et al., 2011). Eddie (2017) has studied he use of nano silica can improve the mechanical properties and durability of high performance concrete (HPC). The allowances for the long-term creep effects in the British Standard and in the Eurocode 2 for the design of reinforced concrete columns have shown some discrepancy (Wong, 1996), while American Society for Testing and Materials International (ASTM) 157 (2009) defines concrete shrinkage test specimens in the beam form.

\footnotetext{
* Corresponding author's email: chatarinaniken@yahoo.com, Tel. +62-81-329055304, Fax. +62-21-7270077 Permalink/DOI: https://doi.org/10.14716/ijtech.v8i5.863
} 
The water to cement ratio influences water distribution and subsequently influences the kinetic properties of concrete, especially shrinkage and creep (Feldman, 1969). Water holds an important role in the volume change mechanism (D'Ambrosia \& Mohler, 2011). High strength concrete (HSC), HPC, and ultra-high performance concrete (UHPC) always use limited water; therefore, their deformation behavior is absolutely different from normal concrete. The absence of coarse aggregate was considered to be a key-aspect for the micro-structure and the performance of UHPC in order to reduce heterogenity between the cement matrix and the aggregate (Adel \& Ahmed, 2015). The use of limited water causes not all ettringite to form at the plastic phase. Ettringite that is formed after the plastic phase leads to early cracking.

Deformation in columns should get more attention because column failure will lead to building collapse. Besides deformation by the hydration process, the effect of column shortening is a major consideration in the design and construction of tall buildings, especially in the concrete and composite structural system. Column shortening occurs because of applied load. Many researchers have been interested in studying deformation. Lampropoulos and Dritsos (2011) have studied the shrinkage behavior of concrete columns with compressive strengths of $24.7 \mathrm{MPa}-$ 30.6 MPa subjected to monotonic and cyclic loading. The creep observation of HSC columns confined by fibre-reinforcements has been published (Ma \& Wang, 2010). The creep behavior of HSC is similar to normal strength concrete, where the creep rate decreases as time increases (Mertol et al., 2010). This statement fits with the shrinkage formula in American Concrete Institute 209R (ACI 209R) (1992). Non-uniform shrinkage and creep in slender concrete frames and columns has been observed (Kawano \& Warner, 1997).

Although the pattern of deformation in many types of structure between HSC and normal concrete are similar, the deformation value varies with the types of structure. The hydration process in columns occurs under pressure conditions from their own weight, making column deformation different from deformation in the beam. Neville (2012) also states that deformation, deflection, strain, and stress distribution are also affected by the type of structure. Until now, there has been no comparison between the long-term deformation of beams and columns, especially for high performance concrete. Based on these explanations, beam and column deformation research is needed.

The purpose of this study was to find the cause of the differences in deformation between beams and columns of high performance concrete.

\section{EXPERIMENTAL PROGRAMME}

The research was conducted in Jakarta, Indonesia, with humid tropical weather. This research was performed experimentally using 5 specimens of $150 \mathrm{~mm} \times 150 \mathrm{~mm} \times 600 \mathrm{~mm}$ according to ASTM C78-08, with one embedded vibrating wire strain gauge (EVWSG) per specimen. Three specimens were layed horizontally to describe a beam, and two specimens were layed vertically to describe a column. The shrinkage at one quarter-high on the column was greater than the shrinkage in the center of the column at up to 180 days (Amir, 2003). The shrinkage in the beam center was affected by the maximum deflection. Based on this study, the position of the EVWSG was at the end of the beam and column, $5 \mathrm{~cm}$ from the specimen tip (Figures 1a and 1b). HPC with a target compressive strength of $60 \mathrm{MPa}$ and slump flow diameter of $35 \pm 2 \mathrm{~cm}$ was used.

\subsection{Materials}

The mix design was conducted in compliance with ACI $211.4 \mathrm{R}(1993)$ with a limit of $500 \mathrm{~kg} / \mathrm{m}^{3}$ cement content to meet the shrinkage factor closest to 1 (ACI 209R, 1992). Ordinary Portland Cement (OPC) produced by Indocement Ltd was used. The condition of the aggregate was saturated surface dry (SSD). Fine aggregate in the form of river sand was brought from Sungai Liat (Bangka, Sumatra, Indonesia), specific gravity (SSD) was 2.605; and absorption was $0.4 \%$. 
The sand had been filtered and cleaned using a mixture of standard graphs obtained from the midgradation. Fine aggregate shall be free of injurious amount of organic impurities (American Society for Testing and Materials International, 2002). Coarse aggregate in the form of volcanic rock fragments was obtained from Banten, West Java, Indonesia. The composition of the coarse aggregate used was $70 \%$ sized $13-19 \mathrm{~mm}$, specific gravity (SSD) of 2.563 , absorption of $1.543 \%$, and $30 \%$ sized $6-12 \mathrm{~mm}$, specific gravity of 2.636 , and absorption of $2.26 \%$. The added material used was silicafume of $8 \%$ cement weight, produced by Sika Indonesia Ltd. To achieve the desired high strength with low ratio of water to cementitious material and good workability, polycarboxylic superplasticizer under the commercial name Visco Crete 10 from Sika Indonesia Ltd was added to the concrete mix as the high range water reducer (HRWR). A dose of HRWR of $1.4 \%$ cement weight was added according to that generally used in Indonesia. Local water was supplied by the Structure and Material Laboratory of Universitas Indonesia. An electrical scale was used for cementitious materials and water to obtain the accurate ratio of water to cementitious material.

The mix composition was $500 \mathrm{~kg} / \mathrm{m}^{3}$ of OPC, $40 \mathrm{~kg} / \mathrm{m}^{3}$ of silica fume, $142.6 \mathrm{~kg} / \mathrm{m}^{3}$ of water, 800 $\mathrm{kg} / \mathrm{m}^{3}$ of sand, $935 \mathrm{~kg} / \mathrm{m}^{3}$ of coarse aggregate, and $7.6 \mathrm{~kg} / \mathrm{m}^{3}$ of HRWR. During the concrete mix design stage, all of the aggregate was assumed to be under saturated surface-dry condition. A tilting drum mixture with a $0.3 \mathrm{~m}^{3}$ capacity was used. The mixing started with all cementitious material in a dry condition, followed with $50 \%$ fine aggregate. Subsequently, $50 \%$ water was added to the revolving mixture. These materials were then mixed for approximately $1 \frac{1 / 2}{2}$ minutes. Next, 50\% water was slowly poured in, which was homogenously mixed with HRWR. Thereafter, $100 \%$ coarse and 50\% fine aggregate were added. With all the materials placed according to their order into the mixer, the concrete was mixed for approximately 3 minutes. The slump flow of the mixture was measured before pouring by using an Abrams cone upside down.

\subsection{Methods}

In this research shrinkage was measured as strain change against time by installing one EVWSG in each specimen (Figures 1a and 1b). The EVWSG able to detect the strain up to $3000 \mu \varepsilon$ with an accuracy of about $.025 \%$ and concrete temperature between $-80^{\circ} \mathrm{C}$ and $60^{\circ} \mathrm{C}$ with about $5 \%$ accuracy. Right after casting, specimens were covered with styrofoam to eliminate water evaporation. The specimens were cured after demolding (one day after casting) by dropping water on the specimens to the age of 7 days. After this treatment, specimens were placed in a conditioned room with a temperature of $28 \pm 3^{\circ} \mathrm{C}$ and relative humidity of $72 \% \pm 5 \%$ (Figure 2) according to the average Indonesian climate. Observation was performed right after pouring as follows: 0-24 hours, every 15 minutes; 24-48 hours, every 60 minutes; days 3-7, every 2 hours; and one time each day using a read out.

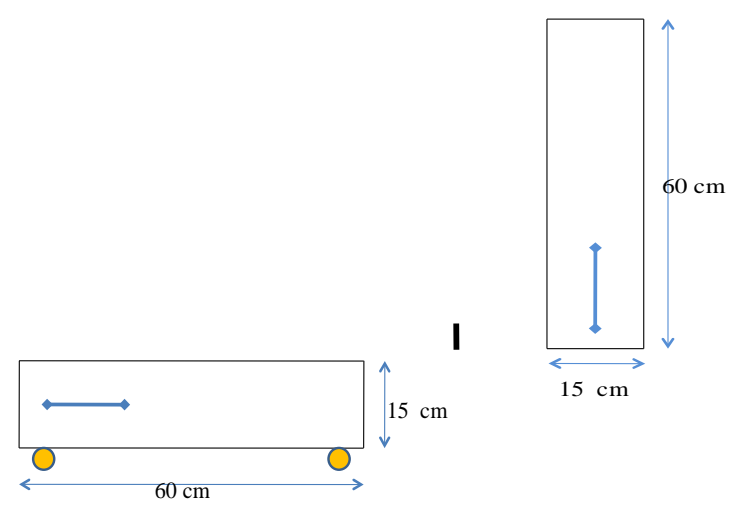

Figure 1 Scheme of specimens with EVXSG $(\longmapsto$ on: (a) Beam; (b) Column 

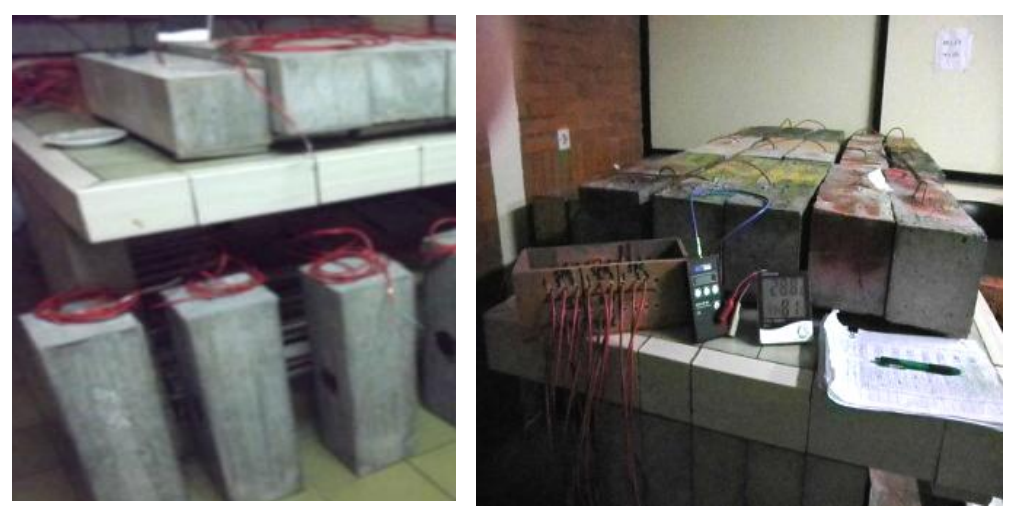

Figure 2 Samples in a conditioned room

Data of the three beam specimens and two column specimens (Figure 3) were analysed using Dixon's criteria as the standard practice for dealing with outlying observation. ASTM E 178-02 has mentioned that Dixon criteria, based entirely on ratios of differences between the observations may be used in cases where it is desirable to avoid calculation of standard deviation or where quick judgment is called for. For a Dixon test, the sample criterion or statistic changes with sample size. The equations of the Dixon criteria for 3 to 7 samples with $\mathrm{x} 1 \leq \mathrm{x} 2 \leq \ldots \leq \mathrm{xn}$ are as follows.

$$
\begin{aligned}
& \text { If smallest value is suspected: } \mathrm{r} 10=(\mathrm{x} 2-\mathrm{x} 1) /(\mathrm{xn}-\mathrm{x} 1) \\
& \text { If largest value is suspected: } \mathrm{r} 10=(\mathrm{xn}-\mathrm{xn}-1)
\end{aligned}
$$

Using Equations 1 and 2 for data at ages 50, 100, 200, 300, and 400, and a 5\% significance level, we anticipated both suspects. By anticipating both suspects, the r10 graph may appear fluctuating and oppositional (Figure 4).

\section{RESULTS AND DISCUSSION.}

\subsection{Result of the Experimental Data and Outlying Analysis}

Long-term deformation of all specimens can be seen in Figure 3.

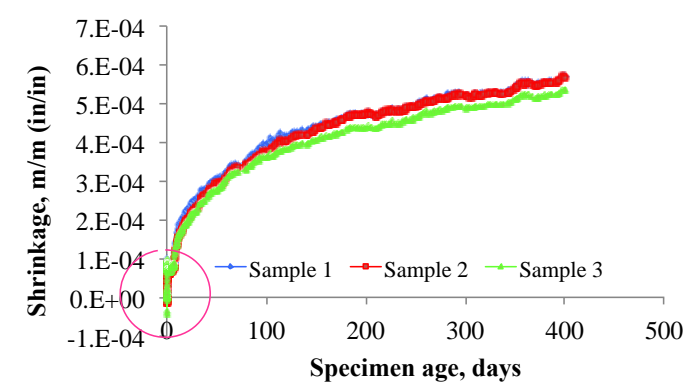

(a)

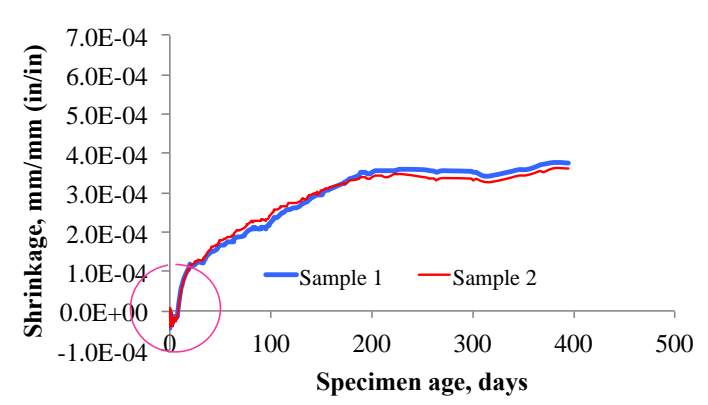

(b)

Figure 3 Long-term deformation of all specimens: (a) Beam; (b) Column. Red circle: difference of deformation occurs at the autogenous phase

There is one datum that exceeds the $5 \%$ level of significance level, i.e., the smallest strain of the beam at 400 days of age (Figure 4); nevertheless, other data are below the 5\% significance level (Figure 4); thus, all data were accepted. 


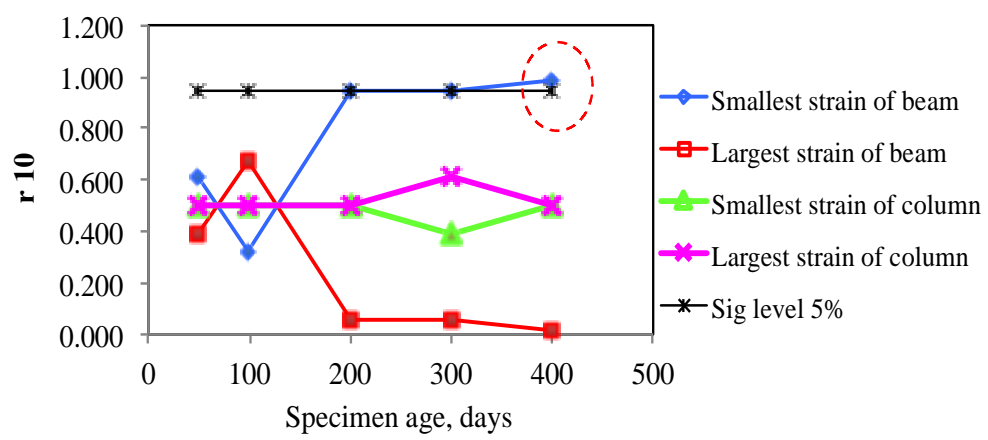

Figure 4 Outlying observation by Dixon's criteria analysis

\subsection{Discussion}

Long-term deformation by shrinkage in columns is lower ( $64 \%$ at the age of 410 days) than shrinkage in beams (Figure 3). Based on Figure 3, the difference of long-term deformation of beams and columns is caused by a difference of deformation at a very early age. The early age deformation is shown in Figure 5a. Figure 5a shows that before the first five hours, a significant difference occurs. Pons (2003) states that deformations in the 3-12 hour range are called autogenous. An autogenous state is a condition without outside influences. In the first hour (the initial period), there are two processes: solution and hydration processes. The characteristic of the solution process is dominant repulsive forces. The solution process (transition zone from solid to liquid) is accompanied by discrete changes of the inner energy terms, such as heat or bond energy. The hydration process begins by the reaction of $\mathrm{C}_{3} \mathrm{~S}, \mathrm{C}_{2} \mathrm{~S}$, and $\mathrm{C}_{3} \mathrm{~A}$. Every chemical reaction accompanies changes of volume, temperature, and bonding forces (Acker, 2004). Alite (pure $\mathrm{C}_{3} \mathrm{~S}$ ) constitutes about $50-80 \%$ of Portland cement, and its hydration makes a major contribution towards the evolution of properties (Kumar et al., 2012). Hydration of alite produces much $\mathrm{Ca}^{2+}$ (Figure 5c). $\mathrm{Ca}^{2+}$ makes the volume swell (Paulini, 1990). Reaction of $\mathrm{C}_{3} \mathrm{~A}$ with water occurs very quickly and liberates much heat. The relationship between the results of this study and Paulini's (1990) study are presented in Figure 5.

Heat is detected as the concrete's temperature. The heat energy of the system becomes the activation energy that makes the particles move. Activation energy is required by the dissociation and solvation mechanism. At the observation point in the column, there was a compressive force coming from the weight of the concrete column above it. The area above the observation point of the column is $40 \mathrm{~cm} \times 15 \mathrm{~cm}$, while above the beam is $7.5 \mathrm{~cm} \times 15 \mathrm{~cm}$; thus, the compression force on the column is larger than the beam. The force squeezed the particles and pores, and, as a result, the particles became solid. Furthermore, the pressure inside the pore became larger than inside the beam.

The pressure kept the pores count down, and thermal conductivity increased (Zulkarnain et al., 2017). The pressures also made the concrete particles in the column more capable dissociating than in the beam; therefore, caused the volume to swell (Taylor, 1997).

This mechanism made the column temperature for the first three hours higher than the beam with high fluctuations (Figure 5b). These fluctuations occurred because the decreasing pores number was affected by the disrupted hydration process because it occurs under pressure.

The type of temperature fluctuation is similar to its deformation (Figures $5 \mathrm{a}$ and $5 \mathrm{~b}$ ), meaning the chemical reaction in column occurred with fluctuating speed. Increasing temperature in specimens of compression also leads to solid volume expansion. Compression force introduces an abnormal expansion of volume (Van Vlack, 1973). According to Arrhenius law, high temperature accelerate chemical reactions (Leenson, 1999); thus, chemical reactions in the columns were faster than in the beams. Faster chemical reactions also make hydration products 
form faster. C-S-H was formed at the age of 3 hours in the columns and 3.5 hours in the beams (Figure 5a).

Swelling in the first hour in the columns was larger than in the beams (Figure 5a). The difference of deformation behaviors between the beams and columns appeared after 30 minutes (Figure 5a). Figure 5a also shows that the beams shrank while the columns continued to swell. Swelling behavior in the columns occurred until the age of 4 hours. Acceleration of sedimentation in the columns was larger than in the beams because of their weight. Repulsive force by the solution process occurred, $\mathrm{Ca}^{2+}$ growth reached its peak (Figure 5c), and high temperature (Figure 5b) combined with the column's weight caused swelling to be abnormal (Figure 5a); therefore, swelling was larger and longer (Figure 5a).

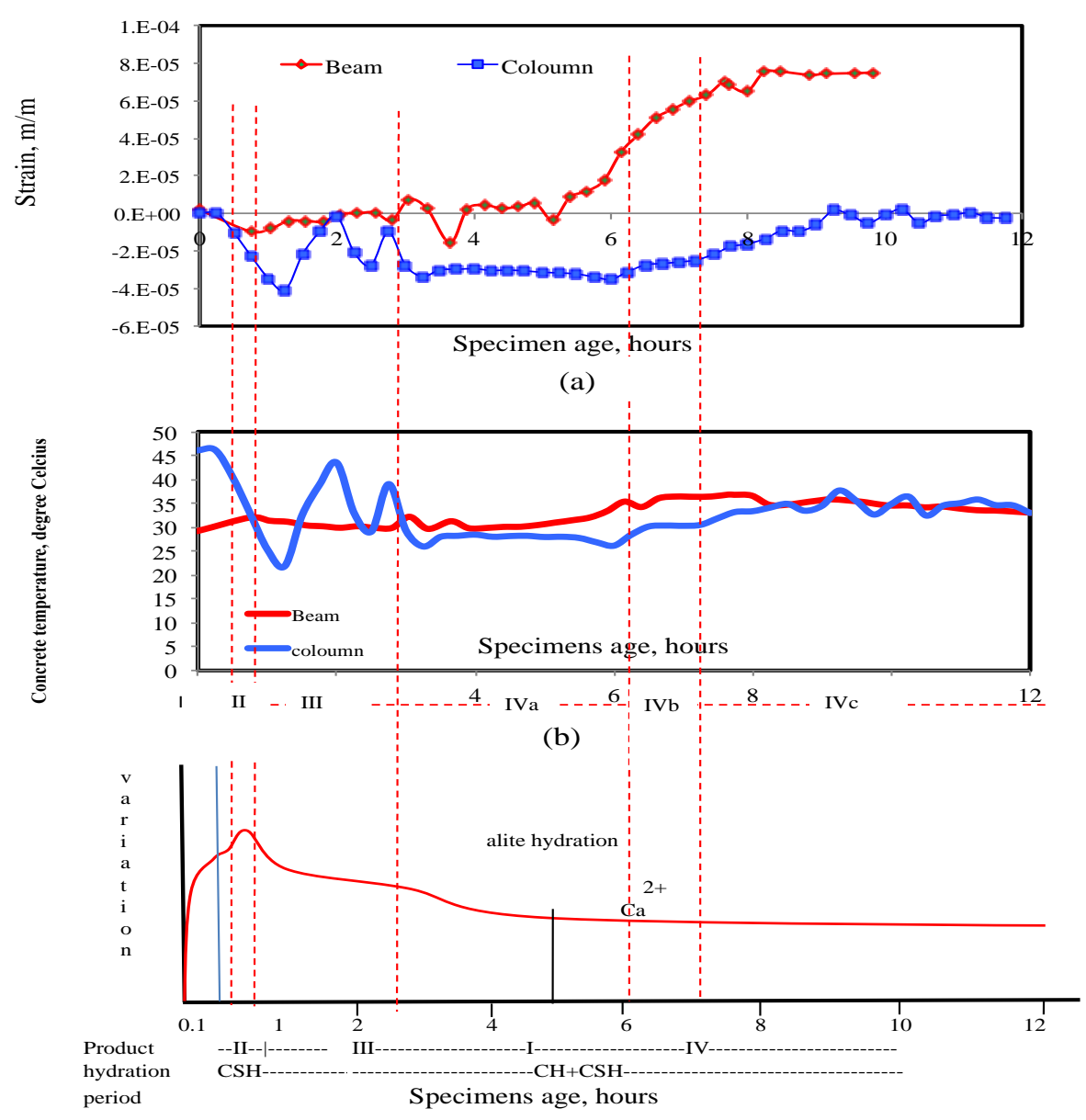

(c)

Figure 5 Relationship between: (a) deformation at early age (this research); (b) concrete temperature (this research); and (c) hydration of alite (Paulini, 1990)

The hydration product volume was smaller than its based component (Thomas \& Jenning, 2008). Thus, the availability of hydration products caused shrinkage. Shrinkage, which is caused by the formation of ettringite and $\mathrm{CH}$ at an early age occurs coincidentally with the swelling as shown in Kurtis (2009). Besides the mechanism mentioned above, the induction process also happened, so the deformation type in concrete took turn at a very early age. It was sometimes balanced between swelling and shrinking, or sometimes swelling was dominant and vice versa (Figure 5a). Within the beams, there was no deformation fluctuation (Figure 5a) because the hydration process occurred without significant pressure. Shrinkage was a major effect, so the influence of hydration product growth was more dominant than the availability of $\mathrm{Ca}^{2+}$ and cement dissociation. 
At the age of $4-6$ hours, $\mathrm{Ca}^{2+}$ gradually decreased (Figure $5 \mathrm{c}$ ), and the deformation rate of the beams and columns was almost stable (Figure 5a). Temperature in the columns and beams was almost similar (Figure 5b). The number of pores also decreased, and, at the same time, hydration products $(\mathrm{C}-\mathrm{S}-\mathrm{H})$ started to grow (Kurtis, 2009). Swelling by $\mathrm{Ca}^{2+}$ and cement dissociation were balanced by shrinkage by C-S-H growth. This condition is shown by the flat line in Figure 5a for beam and column.

From the sixth to the tenth hour, the columns and beams showed curve lines of shrinkage behavior (Figure 5a). The shrinkage phenomenon was caused by the growth of $\mathrm{C}-\mathrm{S}-\mathrm{H}, \mathrm{CH}$, and ettringite at a high rate (Kurtis, 2009 and Figure 6c). The shrinkage rate in the beams was faster than in the columns (Figure 5) because shrinkage in the columns was restrained by the abnormal expansion of volume, so the rate of shrinkage in the columns was slower than in beams. The hydration product growth can be seen in Figure 6 (Taylor, 1997).

From $10^{\text {th }}$ to $12^{\text {th }}$ hour, deformation behavior showed stability (Figure 5a). This means swelling can be balanced by shrinkage (Figures 5, and 6). After this, the beam swelled, but after 18 hours, it shrank, while the column swelled until the age of 24 hours (Figure 7a). This means that in the beams, the influence of an increasing rate of $\mathrm{C}-\mathrm{S}-\mathrm{H}$ and $\mathrm{CH}$ has no restraint, while in the columns the influence of abnormally repulsive forces was still dominant.
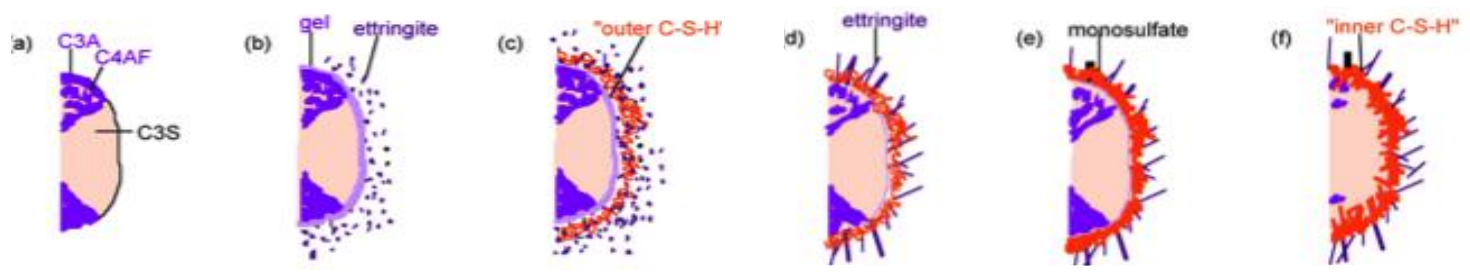

Figure 6 Illustration of product hydration (Taylor, 1997): (a) before hydration; (b) 10 minutes; (c) 10 hours; (d) 18 hours; (e) 1-3 days; (f) 2 weeks

At the age of 24 hours, the samples were de-molded, and then wet curing was applied on all samples. During curing, deformation behavior could be seen as shown in Figure $7 \mathrm{~b}$. The object of curing was to make a high humidity condition; thus, silica bridges could grow optimally, and optimum compressive strength was reached. Both deformations showed a similar type, which was a linear form with a similar rate (Figure $7 b$ ).
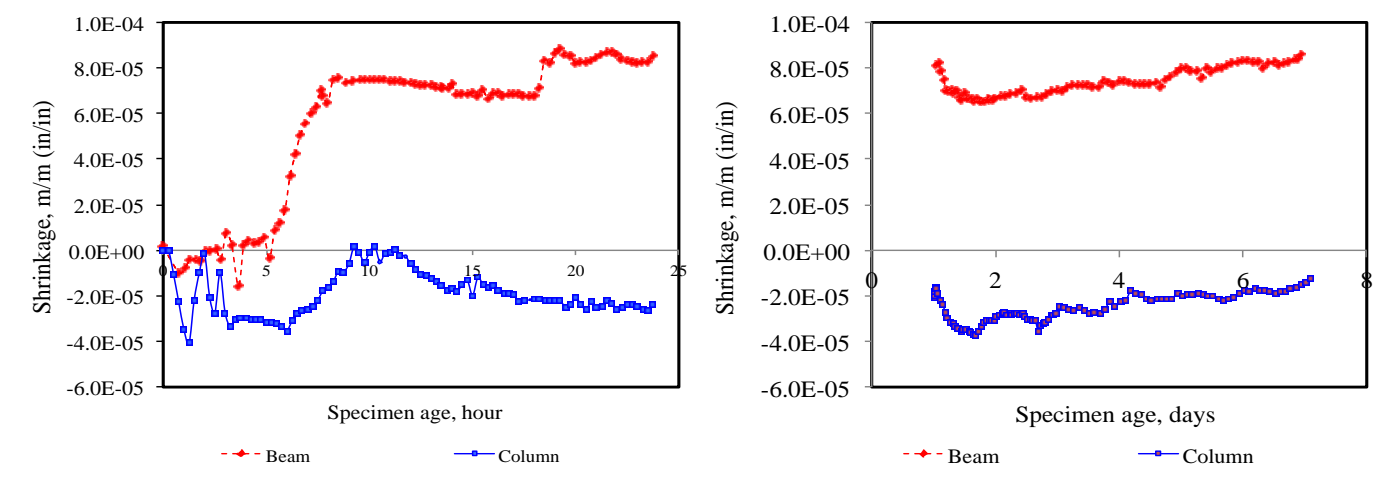

Figure 7 (a) Deformation until 24 hours; (b) deformation during curing

From 7 to 200 days, the deformation rate of the beams and columns had a similar pattern (Figure $3 \mathrm{a}$ and Figure $3 \mathrm{~b}$ ). The enhancement of the deformation rate was exponential. There was no change in the type of deformation in the beams until 410 days, which is indicated by the curved deformation (Figure 3a), but the deformation behavior of the column changed from an arch with 
a sharp slope (because of the high rate of hydration) to a flat or low slope (because of denser particles). The results of this study, especially the deformation of the columns, is in line with Amir (2003). That means that there was a change in deformation rate from fast to slow, or a change in behavior from viscoelastic to strain hardening. This circumstance was caused by the compressive force in the columns, making particles solidify faster than in the beams; concrete particles in the columns were more pressed than in beams, so the deformation rate became very slow (Figure 5a). The autogenous behavior in the column was dominated by abnormal swelling and afterwards behaved normally as mentioned above. In the beam, there is normal behavior from the beginning; thus, the consequence is less shrinkage in the columns than in the beams.

\section{CONCLUSION}

Long-term deformation behavior is determined by autogenous behavior, while autogenous behavior in columns is influenced by abnormal swelling. Abnormal swelling occurs by the fast dissociation of concrete particles because of the concrete's pressure on itself from its own weight, $\mathrm{Ca} 2+$ growth, and the combination of concrete pressure and high hydration temperatures at an early age. In the 1-200 day range, the deformation behavior of the columns showed a similar pattern to the beam (arch). Thereafter (200-410 days), the deformation of the columns became very slow, almost constant (flat), because the particles in the columns became denser. The deformation behavior of the columns showed a similar pattern to that in Amir's study (2003). At the age of 400 days, column deformation was $64 \%$ of beam deformation. This happened when autogenous, abnormal swelling occurred in the column before shrinking. This mechanism did not occur inside the beams.

\section{ACKNOWLEDGEMENT}

I would like to thank all contributors Gabby, Iyang, and Mr. Apri for the helps in preparing column samples and observation, Dr. Yosia I.R., DEA for supplying equipment, and Sika Indonesia Ltd. and Indocement Ltd. for supporting materials. We are grateful to the University of Lampung and Universitas Indonesia, for their support, and generous assistance.

\section{REFERENCES}

ACI Committee 209, 1992. ACI 209R-92: Prediction of Creep, Shrinkage, and Temperature Effects in Concrete Structure, Report No. ACI 209R-82, pp. 1-47

ACI Committee 211, 1993. ACI 211.4R: Guide for Selecting Proportion for High Strength Concrete with Portland Cement and Fly Ash. International Concrete Abstracts Portal, Volume 90, pp. 272-283

Acker, P., 2004. Swelling, Shrinkage and Creep: Mechanical Approach to Cement Hydration, Materials and Structures. International Journal of Concrete Science and Engineering, Volume 37(4), pp. 237-243

American Society for Testing and Materials International, 2002. Standard Practice for Dealing with Outlying Observation, pp. 1-18

American Society for Testing and Materials International, 2009. Construction, Concrete and Aggregates: Standard Specification for Concrete Aggregates, West Conshohocken, pp. $12-18$.

American Society for Testing and Materials International, 2009. Construction, Concrete and Aggregates: Test Method for Flexural Strength of Concrete, West Conshohocken

American Society for Testing and Materials International, 2009. Standard Test Method for Length Change of Hardened Hydraulic Cement Mortar and Concrete, West Conshohocken, pp. 113-119 
Adel, A.A., Ahmed, S.A., 2015. Prediction of Compressive Strength and Ultimate Loads for Reactive Powder Concrete Columns. International Journal of Engineering Sciences, Volume 4(3), pp. 28-38

Adel, A.A., Ahmed, S.A., Husam, K.R., 2011. Behavior of Ultra High Performance Concrete Structures. ARPN Journal of Engineering and Applied Science, Volume 6(5), pp. 95-108

Amir, M., 2003. Final Report for Hybrid FRP Concrete Column, No BD 224. Structural Research Laboratory Florida Department of Transportation, Tallahassee, pp. 1-24

D'Ambrosia, M., Mohler, N., 2011, Early-age Cracking, Concrete Technology. America's Cement Manufacturers, USA

Eddie, J., 2017. Strength Development of High-Performance Concrete using Nanosilica. International Journal of Technology, Volume 8(4), pp. 728-736

Feldman, R.F., 1969. Volume Change and Creep of Concrete, Canadian Building Digest-119, National Government Publication, Canada, USA.

Kawano, A., Warner, R.F., 1997. Non-uniform Shrinkage and Creep in Slender Concrete Frames and Columns. Research Report, Number R150, Department of Civil and Environmental Engineering, The University of Adelaide, pp. 1-17

Kumar, A., Bishnoi, S., Scrivener, K.L., 2012. Modeling Early Age Hydration Kinetics of Alite. Journal of Cement and Concrete Research, Volume 42, pp. 903-918

Kurtis, K., 2009. Portland Cement Hydration. E-Publishing, School of Civil Engineering, Georgia Institute of Technology, Atlanta, Georgia, pp. 1-47

Lampropoulos, A.P., Dritsos, S.E., 2011. Concrete Shrinkage Effect on the Behavior of RC Columns under Monotonic and Cyclic Loading. Journal of Construction and Building Materials, Volume 25, pp. 1,596-1,602

Leenson, I.A., 1999. Old Rule of Thumb and the Arrhenius Equation. Journal of Chemical Education, Volume 76 (10), pp. 1,459-1,467

Ma, Y., Wang, Y., 2010. Parametric Analysis for Creep of High-Strength Concrete Columns Confined by AFRP. In: Proceeding of the $5^{\text {th }}$ International Conference on FRP Composites in Civil Engineering, Beijing

Mertol, H.C., Rizkalla, S., Zia, P., Mirmiran, A., 2010. Creep and Shrinkage Behavior of HighStrength Concrete and Minimum Reinforcement Ratio for Bridge Columns. Journal of PCI, Volume 55(3), pp. 138-154

Morin, V., Cohen-Tenoudji, F., Feylessouti, A., 2002. Evolution of the Capillary Network in a Reactive Powder Concrete during Hydration Process. Journal of Cement and Concrete Research, Volume 32, pp. 1,907-1,914

Neville, A.M., 2012. Properties of Concrete, Prentice Hall, London

Paulini, P., 1990. Reaction Mechanisms of Concrete Admixture. Journal of Cement and Concrete Research, Volume 20(6), pp. 910-918

Pons, G., Munoz, P, Escadeillas, G., 2003. Determination of Concrete Total Deformation under Load as Function of Shrinkage Value. ACI Material Journal, Volume 100, pp. 14-20

Taylor, H.F.W., 1997. Cement Chemistry, Thomas Telford, London

Thomas, J., Jenning, H., 2008. The Science of Concrete, American Concrete Association, Center of Advance Concrete Based Materials Research, iti.northwestern.edu.

Van Vlack, L.H, 1973. Materials Science for Engineers, Addison Wesley, Canada, USA

Wong, A.F.L., Arnaouti, C., Raji, Ms.N.K., 1996. Effects of Concrete Creep on the Ultimate Compressive Strength of Concrete Columns, In: Appropriate Concrete Technology, pp. 99-107

Zulkarnain, M., Fadzil, M.A., Sharudin, R., 2017. Algorithm of Pores Distribution Model for Analysis and Measurement of Thermal Conductivity of Polypropylene Porous Materials. International Journal of Technology, Volume 8(3), pp. 398-407 